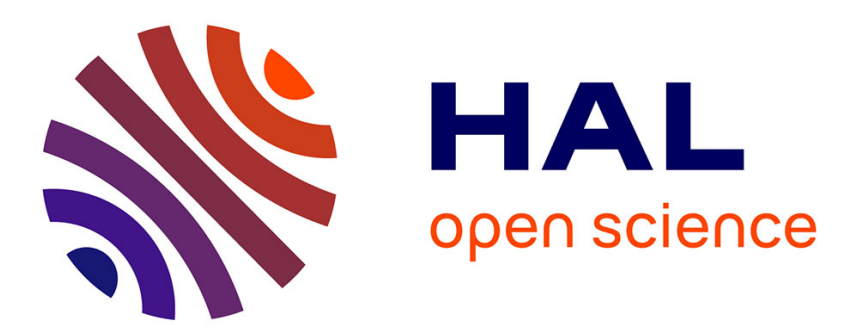

\title{
The effect of annealing on magnetic properties of Co/Gd multilayers
}

\author{
S. Vorobiov, Ia. Lytvynenko, Thomas Hauet, Michel Hehn, D. Derecha, A.
}

Chornous

\section{> To cite this version:}

S. Vorobiov, Ia. Lytvynenko, Thomas Hauet, Michel Hehn, D. Derecha, et al.. The effect of annealing on magnetic properties of $\mathrm{Co} / \mathrm{Gd}$ multilayers. Vacuum, 2015, 120 (A), pp.9-12. 10.1016/j.vacuum.2015.06.009 . hal-01284011

\section{HAL Id: hal-01284011 \\ https://hal.science/hal-01284011}

Submitted on 19 Jul 2016

HAL is a multi-disciplinary open access archive for the deposit and dissemination of scientific research documents, whether they are published or not. The documents may come from teaching and research institutions in France or abroad, or from public or private research centers.
L'archive ouverte pluridisciplinaire HAL, est destinée au dépôt et à la diffusion de documents scientifiques de niveau recherche, publiés ou non, émanant des établissements d'enseignement et de recherche français ou étrangers, des laboratoires publics ou privés. 


\title{
The effect of annealing on magnetic properties of $\mathrm{Co} / \mathrm{Gd}$ multilayers
}

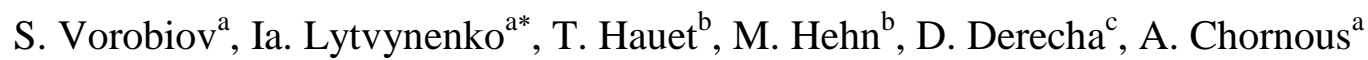 \\ ${ }^{a}$ Sumy State University, Rymskogo-Korsakova 2, 40007 Sumy, Ukraine \\ ${ }^{b}$ Institut Jean Lamour, UMR CNRS 7198, Université de Lorraine, 54506 \\ Vandoeuvre-les-Nancy, France \\ ${ }^{c}$ Institute of Magnetism NAS and MOE of Ukraine, Akad. Vernadskogo 36-b, 03142 \\ Kyiv, Ukraine
}

\begin{abstract}
The impact of annealing on the structural and magnetic properties of sputtered $[\mathrm{Gd} / \mathrm{Co}]_{\mathrm{n}}$ multilayers has been researched. Structural and phase contrast of atomic force microscope measurements at the imaging of the facet sample cross-section demonstrate that thermal annealing process at $700 \mathrm{~K}$ leads to intermixing between Co and Gd layers, i.e. the alloy formation around the former interface. Magnetometry measurements are coherent with such CoGd alloying. Annealing reinforces the domination of domain wall propagation in the magnetization reversal mechanism. Low temperature magnetometry analysis seems to indicate that CoGd mixing due to annealing may occurs over $2 \mathrm{~nm}$ apart from initial $\mathrm{Co} / \mathrm{Gd}$ interface.
\end{abstract}

Keywords: multilayers, annealing, interface alloying, magnetization, coercivity.

Rare Earths (REs) - Transition Metals (TMs) ferrimagnetic alloys or multilayers have a great importance in modern magnetism because of their unique properties due to their 4f orbitals: perpendicular magnetic anisotropy [1-3], antiferromagnetic exchange-

*yarina.litvinenko@gmail.com 
coupling in multilayers or alloys with both REs and TMs [4-5] and frozen frustrated magnetic state [6]. The variation of RE/TM concentration allows controlling the magnetic and magnetotransport properties of the system, as well as alignment of its magnetic moment with the external magnetic field [1-3] or inverse GMR [7]. Magnetic multilayers, like $\mathrm{Co} / \mathrm{Gd}, \mathrm{Co} / \mathrm{Tb}, \mathrm{Co} / \mathrm{Dy}$ or $\mathrm{Co} / \mathrm{Ho}$ have been recently used as model systems to study the intrinsic mechanism of circularly polarized light induced switching $[8]$.

Despite a very active research of REs - TMs systems, many things are still unclear especially in multilayers. Indeed, the properties of RE/TM multilayers have been widely studied in the past $[4-5,9-11]$ but the influence of heat treatment on the magnetic behavior of multilayers has not been enough researched. It has also been shown that interfacial magnetic disorder [12] impacts the magnetism and affects to the magnetization reversal processes [13]. In this article, we report experimental researches of the magnetic properties in $\mathrm{Gd} / \mathrm{Co}$ multilayers with various Co layer thicknesses and $[\mathrm{Gd} / \mathrm{Co}]$ repeats number and the effect of thermal annealing on those properties. Lateral AFM measurements and magnetometry measurements demonstrate that a $700 \mathrm{~K}$ annealing leads to an inter-diffusion over more than $2 \mathrm{~nm}$ apart from the interface.

$\mathrm{Si} / \mathrm{SiO} / \mathrm{Ta}(5 \mathrm{~nm}) / \mathrm{Pt}(5 \mathrm{~nm}) /[\mathrm{Co}(\mathrm{x}) / \mathrm{Gd}(2 \mathrm{~nm})]_{\mathrm{n}} / \mathrm{Ta}(2 \mathrm{~nm}) / \mathrm{Pt}(5 \mathrm{~nm})$ and $\mathrm{Si} / \mathrm{SiO} / \mathrm{Ta}(5 \mathrm{~nm}) /$ $\mathrm{Pt}(5 \mathrm{~nm}) / \mathrm{Co}(3.5 \mathrm{~nm}) / \mathrm{Gd}(7 \mathrm{~nm})] / \operatorname{Co}(3.5 \mathrm{~nm}) / \mathrm{Ta}(2 \mathrm{~nm}) / \mathrm{Pt}(5 \mathrm{~nm})$ multilayers were grown by sputtering at room temperature under a pressure of $5 \times 10^{-3}$ mbar of $\mathrm{Ar}$ in a UHV chamber with base pressure less than $5 \times 10^{-9}$ mbar. The Co layer thicknesses $(\mathrm{x})$ were chosen equal to 2 or $5 \mathrm{~nm}$. The number of Co/Gd bilayer repeats (n) was varied from 2 to 8 . A $\mathrm{SiO}(100 \mathrm{~nm}) / \mathrm{Ta}(5 \mathrm{~nm}) / \mathrm{Pt}(5 \mathrm{~nm})$ buffer layer was used to prevent mixing of $\mathrm{Si}$ with the multilayer stack during annealing procedure. The multilayers were capped with 
$\mathrm{Ta}(2 \mathrm{~nm}) / \mathrm{Pt}(5 \mathrm{~nm})$ bilayer to protect them from oxidation. After deposition, the multilayers were either annealed in high vacuum chamber at $700 \mathrm{~K}$ for 20 minutes or kept without thermal treatment. The X-ray diffraction (XRD) was used for the research of samples phase state before annealing. The study of structural changes due to annealing has been performed using AFM (NT-MDT Solver Pro MFM) imaging on cross-section of the facet sample, as a result of semi-contact two-pass scanning. A cross-section was done at small angle to the sample plane $\left(10-12^{\circ}\right)$. As a result we have got much bigger area of the researched sample. Both the structural and phase contrast microscopy of the multilayer were performed in order to obtain more detailed information about the samples structure. Magnetic characterizations were performed at $300 \mathrm{~K}$ and $10 \mathrm{~K}$ using both a commercial vibrating sample magnetometer (VSM) and a commercial SQUID-VSM.

A phase composition studying by means of X-ray diffraction showed that the asdeposited multilayers consist of the hcp-Co + fcc-Co + quasi amorphous Gd. Quasiamorphous state of $\mathrm{Gd}$ is characterized by the existence only the nearest crystalline order or by the beginning of crystallization process in Gd layer which is confirmed by the presence only so called "halo" on the electron diffraction patterns and absence the clear rings on it which we showed in our previous works for $\mathrm{Gd}$ and $\mathrm{Co} / \mathrm{Gd} / \mathrm{Co}$ system [14-16] that also has a good agreement with literature data [23-25]. As a first step in the specification of the influence of the $700 \mathrm{~K}$ annealing process on $\mathrm{Co} / \mathrm{Gd}$ interfaces was defined if the layered structure of the samples has been maintained. In Fig. 1 the AFM phase contrast cross-section image of $\operatorname{Co}(3.5 \mathrm{~nm}) / \mathrm{Gd}(7 \mathrm{~nm}) / \mathrm{Co}(3.5 \mathrm{~nm})$ sample demonstrates presence of interlayers between $\mathrm{Gd}$ and Co after annealing. Annealing causes a phase transition hcp-Co $\rightarrow$ fcc-Co at $700 \mathrm{~K}$ and consequently the 
recrystallization process with Co grains size growth which led to the interface morphology changes and penetration of Co into Gd layer and vice versa - Co and Gd are mixing. As Co and Gd are not soluble in each other in the solid state we can conclude that theoretically we received a mechanically mixed alloy of crystalline Co and amorphous Gd. Very similar results were observed by authors [17-19] as for intermixing between $\mathrm{Co}$ and $\mathrm{Gd}$ layers with amorphous CoGd alloy formation. The substantial aliquot deviation between the measured and declared layers on Fig. 1 can be explained by the peculiarities of the measurement and sample preparation technics (the mutual orientation between facet sample and cantilever and the non-perpendicularity of the cross-section). Figure 2 shows magnetization curves of $[\operatorname{Co}(5 \mathrm{~nm}) / \operatorname{Gd}(2 \mathrm{~nm})]_{\mathrm{n}}$ multilayers with different numbers of repeats $(n=2 ; 4 ; 6 ; 8)$ before (a) and after (b) annealing measured under in-plane applied magnetic field. The influence of repeats number on coercive field $\left(\mathrm{H}_{\mathrm{C}}\right)$ of non-annealed samples is weak (Fig. 2 (a)). First of all, after thermal anneal, $\mathrm{H}_{\mathrm{C}}$ for both $[\mathrm{Co}(5 \mathrm{~nm}) / \mathrm{Gd}(2 \mathrm{~nm})]_{\mathrm{n}}$ and $[\operatorname{Co}(2 \mathrm{~nm}) / \operatorname{Gd}(2 \mathrm{~nm})]_{\mathrm{n}}$ increases. Secondly, it increases and varies linearly with the number of repeats as shown in Fig. 2 (b, c). One of the possible reasons for such behavior is the increase of interface roughness with annealing that affects the domain walls propagation and therefore $\mathrm{H}_{\mathrm{C}}$. The impact of interface diffusion would increase with the number of interface, i.e. with the number of repeats.

To confirm the role of domain wall motion in the magnetization reversal mechanism in $\mathrm{Co} / \mathrm{Gd}$ multilayers, we measured coercivity as a function of external magnetic field angle. In Fig. 3, the coercivity is found to drastically increase as the field angle approaches $90^{\circ}\left(0^{\circ}\right.$ being a direction in the film plane and $90^{\circ}$ the direction perpendicular to the film). Such behavior is typical for materials with in-plane 
anisotropy and for magnetization reversal process that is dominated by domain wall propagation [20]. The same behavior is found to be similar for all samples whatever the repeats number is. One can notice that the increase close to $90^{\circ}$ is much larger for annealed sample. Moreover one can notice that this increase is also much larger for $n=8$ sample (Fig. 3 (b)) as compared to the $n=2$ sample (Fig.3 (a)). So it seems that indeed the domain wall propagation influence is enhanced by the annealing process and that the number of repeats matters. It confirms that most probably the coercivity increasing along with the increasing of repeats number connects with alloying formation on $\mathrm{Co} / \mathrm{Gd}$ interface that creates the pinning center for domain wall.

To further confirm the intermixing at the $\mathrm{Co} / \mathrm{Gd}$ interface during annealing, we focused on $[\mathrm{Co}(2) / \mathrm{Gd}(2)]_{4}$. The normalized magnetization versus field loop recorded at $300 \mathrm{~K}$ and $10 \mathrm{~K}$ are shown in Fig. 4. As seen in Fig. 4 (a), at $300 \mathrm{~K}$, single hysteresis loop is observed for non-annealed $[\mathrm{Co}(2) / \operatorname{Gd}(2)]_{4}$. At room temperature, bulk Gd is paramagnetic because of its low Curie temperature (292 K). Nevertheless, one has to notice that stabilization of ferromagnetism in $\mathrm{Gd}$ for temperature up to $350 \mathrm{~K}$ has already been reported and explained by the exchange coupling at the interface with Co [10-11]. In our case, Fig. 4 (a) does not reveal any exchange coupling features at $300 \mathrm{~K}$. At low temperature $(10 \mathrm{~K})$ the hysteresis loop shape for non-annealed sample is more complex (Fig. 4 (a)). At this temperature Gd is expected to be ferromagnetic with the bulk saturation magnetization $\mathrm{M}_{\mathrm{Gd}}=2056 \mathrm{emu} / \mathrm{cm}^{3}$, while $\mathrm{M}_{\mathrm{Co}}$ is $1400 \mathrm{emu} / \mathrm{cm}^{3}$.

The $10 \mathrm{~K}$ hysteresis loops are typical for antiferromagnetic interface exchange coupling between Co and Gd [6]. At zero field, $\mathrm{M}_{\mathrm{Gd}}$ being larger than $\mathrm{M}_{\mathrm{Co}}$, Gd moments align to the field while Co align is antiparallel to it due to anti-ferromagnetic exchange coupling. When the field amplitude is increased, the competition between Zeeman 
energy and interface exchange coupling leads to a slow monotonous rotation of Co moments along the magnetic field direction. The total magnetization increases.

After annealing, although the single reversal at $300 \mathrm{~K}$ remains, magnetization versus field loop at $10 \mathrm{~K}$ has strongly changed. Indeed no plateau is observed at remanence (Fig. 4 (b)). Only single reversal occurs which $\mathrm{Co} / \mathrm{Gd}$ multilayers have been changed into a single CoGd alloy through the annealing process. The fact that saturation is reached only around 2 Tesla can be related to either a reminiscent CoGd pure layer in a $\mathrm{Co} / \mathrm{GdCo} / \mathrm{Gd}$ stacking or due to amorphous alloy random anisotropy.

One can calculate the expected concentration of the CoGd alloy that is created at the $\mathrm{Co} / \mathrm{Cd}$ interface during annealing using equation (1) and assuming that the alloying occurs within the same thickness on both side of the interface [21]:

$$
c_{C o}=\frac{D_{C o} d_{C o} \mu_{C o}^{-1}}{D_{C o} d_{C o} \mu_{C o}^{-1}+D_{G d} d_{G d} \mu_{G d}^{-1}}
$$

where $D$ corresponds to density, $\mu$ - to molar mass of elements and $d-$ to effective film thickness for each layer.

The concentration of $\mathrm{Co}$ is found to be $75 \%$ if $[\mathrm{Co}(2) / \mathrm{Gd}(2)]_{4}$ transforms into alloy. Hence, the present alloy $\mathrm{Gd}_{25} \mathrm{Co}_{75}$ is $\mathrm{Gd}$-dominant and the net magnetization is parallel to the Gd sublattice since the compensation composition $\left(\mathrm{M}_{\text {alloy }}=0\right)$ of $\mathrm{Gd}$ in $\mathrm{Gd}_{\mathrm{x}} \mathrm{Co}_{1-\mathrm{x}}$ alloy is $20 \%$ at $5 \mathrm{~K}[1,22]$. Inside the alloy Co moments reversal along the field would require 10 Tesla that is way it does not appears in Fig. 4 (b).

In summary, magnetization of $[\mathrm{Gd} / \mathrm{Co}]_{\mathrm{n}}$ multilayers before and after annealing at $700 \mathrm{~K}$ were studied. AFM measurements demonstrate that annealing leads to 
intermixing between Co and Gd layers, i.e. the formation of the amorphous alloy around the former interface. Magnetometry measurements show that domain wall propagation is dominated at the reversal process. Co/Gd interface alloying due to annealing causes pinning against domain wall motion and the coercivity increase is proportional to the number of interface in the initial multilayer stack. Low temperature magnetometry analysis seems to indicate that CoGd mixing due to annealing may occur over $2 \mathrm{~nm}$ apart from initial $\mathrm{Co} / \mathrm{Gd}$ interface.

\section{Acknowledgments}

This work was partly financed under support of the State budget program Nr. 0112U004688 and Ministry of Education and Science of Ukraine for research training abroad (individual grants).

\section{References}

[1] Gottwald M, Hehn M, Montaigne F, Lacour D, Lengaigne G, Suire S, and Mangin S. J Appl Phys 2012; 111: 083904.

[2] Nakayama M, Kai $T$, Shimomura N, Amano M, Kitagawa E, Nagase $T$, Yoshikawa M, Kishi T, Ikegawa S, Yoda H. J Appl Phys 2008; 103: 07A710.

[3] Ye L-X, Lee C-M, Lai J-H, Canizo-Cabrera A, Chen W-J, Wu T-H. J Magn Magn Mater 2011; 322: L9.

[4] Fujiwara Y, Masaki T, Yu XY, Sakurai M, Tsunashima S. Jpn J Appl Phys 1997; 36: 5097.

[5] Kubota Y, Wu X, Ju G. J Magn Magn Mater 2007; 310: 2665. 
[6] Hauet T, Borchers JA, Mangin Ph, Henry Y, and Mangin S. Phys Rev Lett 2006; 96: 067207.

[7] Bellouard C, Rapp HD, George B, Mangin S, Marchal G, and Ousset JC. Phys Rev B 1996; 53: 5082.

[8] Mangin S, Gottwald M, Lambert C-H, Steil D, Uhlír V, Pang L, Hehn M, Alebrand S, Cinchetti M, Malinowski G, Fainman Y, Aeschlimann M, Fullerton EE. Nat Mater 2014; $13: 286$.

[9] Vettier C, McWhan DB, Gyorgy EM, Kwo J, and Buntschuh BM. Phys Rev Lett 1986; 56: 757.

[10] Romera M, Munoz M, Maicas M, Michalik JM, de Teresa JM, Magen C, and Prieto JL. Phys Rev B 2011; 84: 094456.

[11] Haskel D, Srajer G, Lang JC, Pollmann J, Nelson CS, Jiang JS, and Bader SD, Phys Rev Lett 2001; 87: 207201.

[12] Takano K, Kodama RH, Berkowitz AE, Cao W, and Thomas G. Phys Rev Lett 1997; 79: 1130

[13] Berger A, Inomata A, Jiang JS, Pearson JE, Bader SD. Phys Rev Lett 2000; 85: 4176.

[14] Vorobiov SI, Cheshko IV, Chornous AM, Shirzadfar H, Shutylieva OV. J NanoElectron Phys 2014; 6 (2): 02022.

[15] Vorobiov SI, Cheshko IV, Chornous AM, Shpetnyi IO. Metallofiz Noveishie Tekhnol 2013; 35 (12): 1645.

[16] Vorobiov SI, Shutileva OV, Shpetnyi IO, Chornous AM. J Nano- Electron Phys 2012; 4 (4): 04026. 
[17] Alonso JA, Hojvatde Tendler R, Barbiric DA, Riveiro JM. J Phys: Condens Matter 2002; 14: 8913.

[18] Colino J, Andres JP, Riveiro JM, Martınez L, Prieto C, and Sacedon JL. Phys Rew B 1999; 60 (9): 6678.

[19] Andres JP, Sacedon JL, Colinoa J, and Riveiro JM. J Appl Phys 2000; 87(5): 2483.

[20] Kondorsky E. J Phys Moscow 1940; 2: 161.

[21] Protsenko SI, Cheshko IV, Velykodny DV, Pazukha IM, Odnodvorets LV, Protsenko IYu, Synashenko OV. Uspehi Fiziki Metallov 2007; 8: 247.

[22] Hansen P, Clausen C, Much G, Rosenkranz M, and Witter K. J Appl Phys 1989; 66 (2): 756.

[23] Vaskovsky VO, Svalov AV, Gorbunov AV, Shchogeleva NN, Zadvorkin SM. Solid State Phys 2001; 43 (4): 672. (Rus.)

[24] Protsenko IYu, Cheshko IV. Visnyk SumDU: Physics, mathematics, mechanics 2005; 24: 137. (Ukr.)

[25] Vaskovsky VO. Magnetism of nanosystems based on rare-earth and 3d-transition metals: chrestomathy (Yekaterinburg IONTS: 2007). (Rus.)

Fig.1. AFM phase contrast image of the cross-section of Co $(3.5 \mathrm{~nm}) / \mathrm{Gd}(7 \mathrm{~nm}) / \mathrm{Co}(3.5 \mathrm{~nm})$ three-layer sample on the amorphous glassceramic substrate after annealing at $700 \mathrm{~K}$ 
Fig.2. Normalized magnetization as a function of magnetic field, applied in the film plane for the $[\operatorname{Co}(5 \mathrm{~nm}) / \operatorname{Gd}(2 \mathrm{~nm})]_{\mathrm{n}}$ multilayers measured at room temperature before (a) and after (b) annealing. (c) Coercivity as a function of repeats number of $[\mathrm{Co}(\mathrm{x}) / \mathrm{Gd}(2 \mathrm{~nm})]$ stack in multilayers measured at room temperature before and after annealing

Fig.3. Coercivity as a function of angle for $[\operatorname{Co}(5 \mathrm{~nm}) / \operatorname{Gd}(2 \mathrm{~nm})]_{2}$ (a) and $[\mathrm{Co}(5 \mathrm{~nm}) / \mathrm{Gd}(2 \mathrm{~nm})]_{8}$ (b) multilayers before and after annealing at $700 \mathrm{~K}$

Fig.4. Normalized magnetization as a function of magnetic field applied in-plane, measured for $[\operatorname{Co}(2 \mathrm{~nm}) / \mathrm{Gd}(2 \mathrm{~nm})]_{4}$ system at $300 \mathrm{~K}$ and $10 \mathrm{~K}$ for samples before (a) and after annealing (b) 


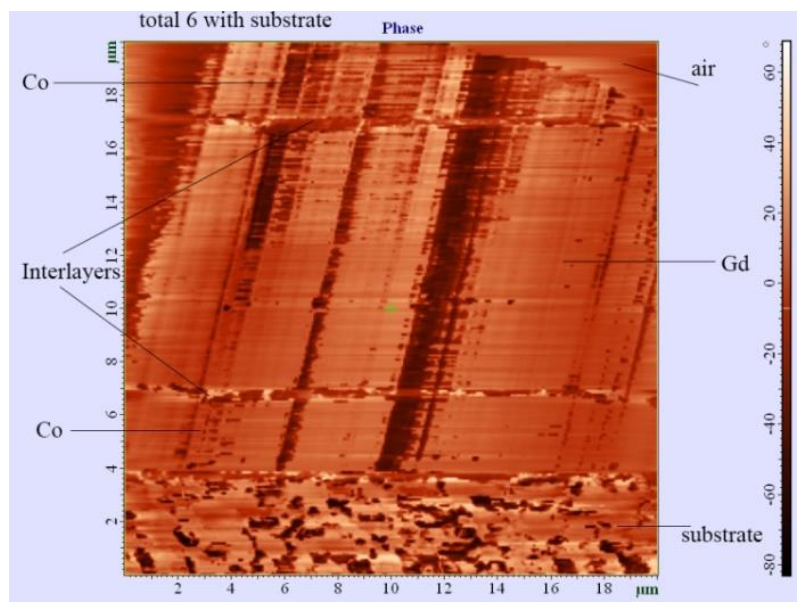

Fig.1. 

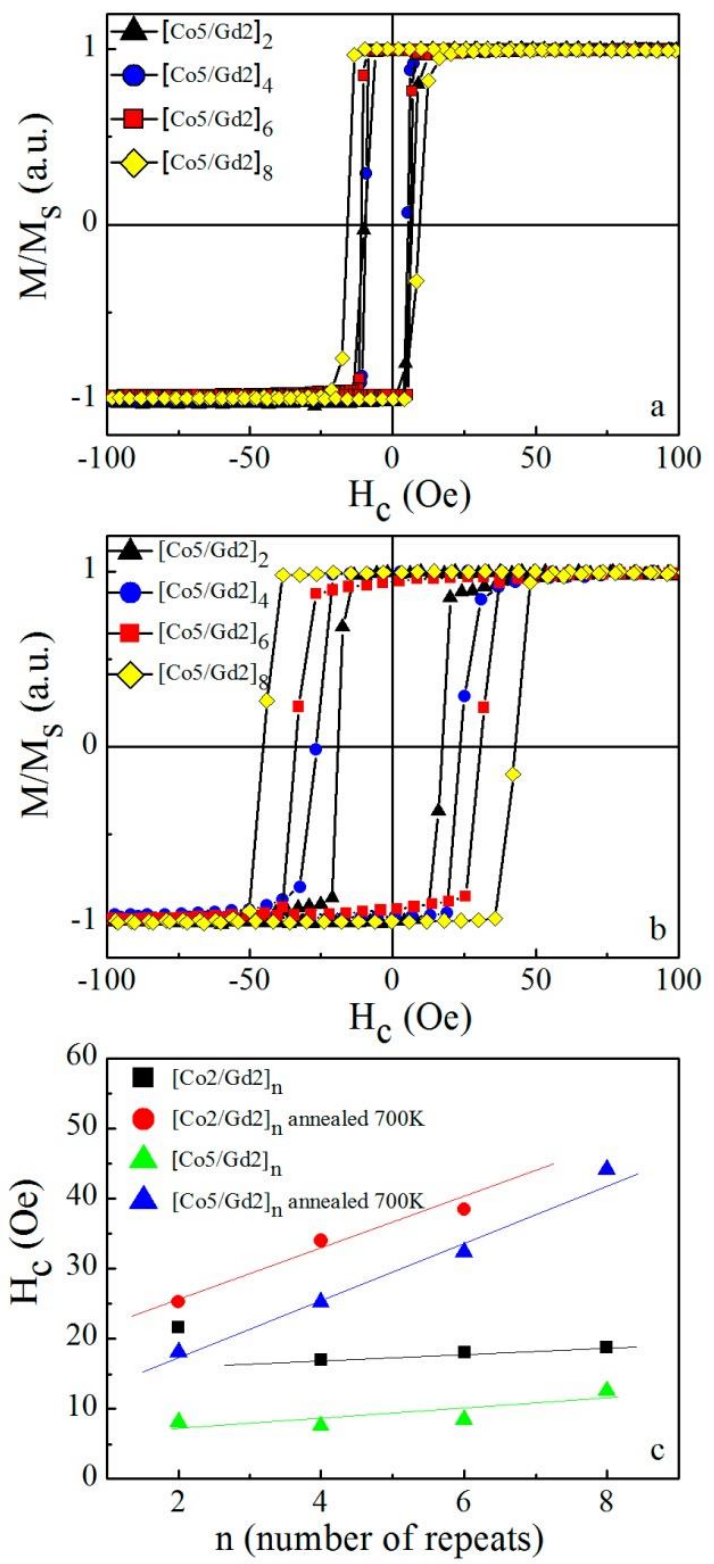

Fig.2. 

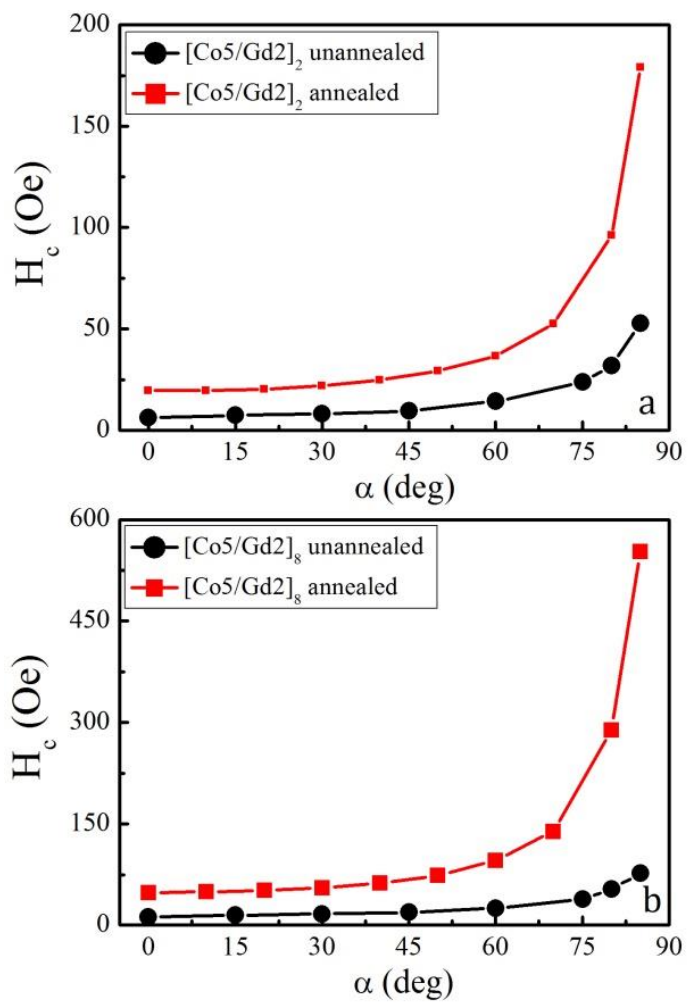

Fig.3.
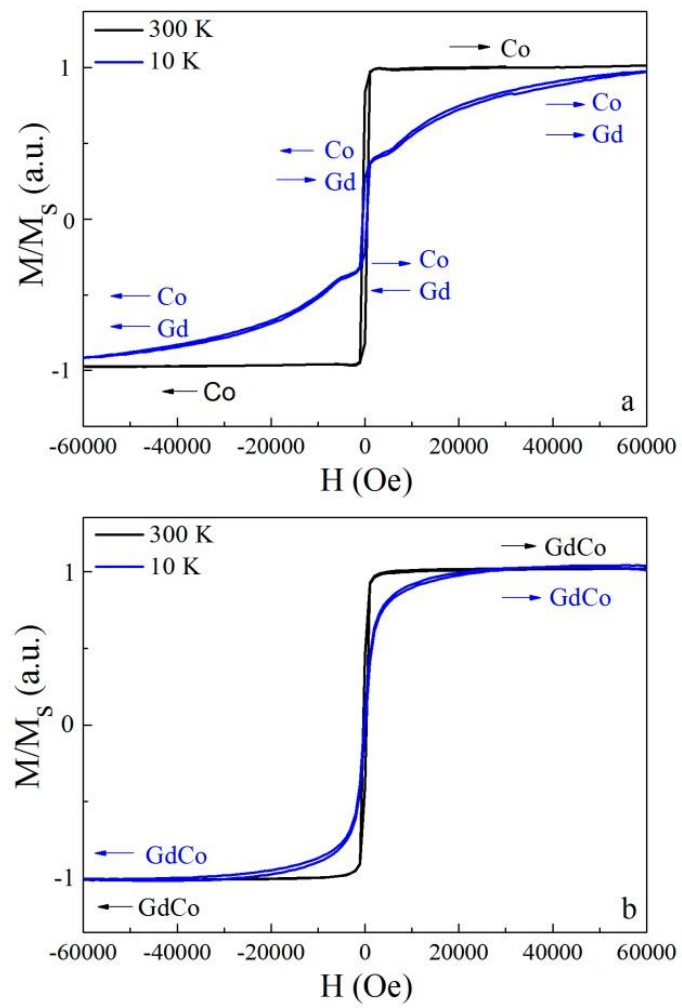

Fig.4. 